\title{
Diagenetic effect on magnetic properties of marine core sediments from the southern Okhotsk Sea
}

\author{
Noriko Kawamura $^{1}$, Hirokuni Oda ${ }^{2}$, Ken Ikehara $^{2}$, Toshitsugu Yamazaki ${ }^{2}$, Kumi Shioi $^{3}$, Shunsuke Taga ${ }^{3}$, \\ Shinsyo Hatakeyama ${ }^{3}$, and Masayuki Torii ${ }^{3}$ \\ ${ }^{1}$ Graduate School of Human and Environmental Studies, Kyoto University, Yoshida-nihonmatsu-cho, Kyoto 606-8501, Japan \\ ${ }^{2}$ Institute of Geology and Geoinformation, Geological Survey of Japan, AIST, Tsukuba 305-8567, Japan \\ ${ }^{3}$ Department of Biosphere - Geosphere System Science, Okayama University of Science, Okayama 700-0005, Japan
}

(Received February 20, 2006; Revised September 23, 2006; Accepted October 2, 2006; Online published March 21, 2007)

\begin{abstract}
It is well known that magnetic records of marine sediments are affected to a certain degree by early diagenesis, the extent and mode of which are controlled by depositional environments. In order to investigate variations in the effects of early diagenesis, we have analyzed 11 gravity cores estimated to be Holocene in age that constitute a depth transect off the southern coast of the Okhotsk Sea. The rock magnetic parameters have peaks produced by the presence of volcanic ashes, basaltic granules and/or relatively coarser-grained layers. The concentrationdependent parameters display characteristic trends of a rapid decrease within the homogeneous silty clay zone in the middle parts of the cores, assuming that the total amount of magnetic minerals decreases through early diagenesis at this interval. This decrease is found in all of the cores from the transect (from both near-shore and offshore sites). In near-shore sites where larger volumes of organic materials are supplied compared to offshore sites, the depth of the decrease in magnetic minerals is relatively shallow. These results imply that the presence of organic materials accelerates the pyritization through the bacterial reduction of ferric ion, thereby causing the decreases in magnetic minerals to become shallower.
\end{abstract}

Key words: Rock magnetic parameters, early diagenesis, magnetite, hematite, selective dissolution.

\section{Introduction}

Rock magnetic analysis of marine sediments has been widely used in paleomagnetic, paleoenvironmental and paleoclimatological studies (e.g., Walden et al., 1999; Evans and Heller, 2003). In the case of marine sediments having high sedimentation rates, however, a straightforward interpretation has been hindered due to post-depositional diagenetic degradation of rock magnetic records. The dissolution and neo-formation of magnetic minerals have been reported from the continental slope sediments (e.g., Yamazaki et al., 2003; Liu et al., 2004), and the dissolution of magnetic minerals has been reported in deep-water shelf-basin sediments (e.g., Leslie et al., 1990a, b) and also in hemipelagic or abyssal sediments (e.g., Torii, 1997; Robinson et al., 2000). Therefore, the evaluation of diagenetic effects on rock magnetic properties is essential in studies on marine sediments.

The Okhotsk Sea is a semi-closed marginal sea located on the western rim of the Northwest Pacific Ocean. It has a generally cyclonic current system and exchanges water with the Pacific through the Kurile Islands (Fig. 1). The Okhotsk Sea is one of the southernmost extents of sea ice in the northern hemisphere, and it is the largest seasonally icecovered area in the world. The southern part of Okhotsk Sea, off Abashiri, is known to be the region where the Soya warm current sinks in early spring (Takizawa, 1982;

Copyright (c) The Society of Geomagnetism and Earth, Planetary and Space Sciences (SGEPSS); The Seismological Society of Japan; The Volcanological Society of Japan; The Geodetic Society of Japan; The Japanese Society for Planetary Sciences; TERRAPUB.
Watanabe and Wakatsuchi, 1998; Kimura and Wakatsuchi, 1999). The winter air-mass modification over the Okhotsk Sea influences not only the local atmospheric field but also larger scale circulations (e.g., Takahashi, 1998).

The sedimentation rates of the southern Okhotsk Sea have been determined to have been generally high (approx. $150 \mathrm{~cm} / \mathrm{ky}$ ) during the Holocene. Additionally, the presence of widespread tephras originating from the volcanoes in Hokkaido may provide good time-markers for marine sediments in the southern Okhotsk Sea (Shimada et al., 2000; 2004; Gorbarenko et al., 2002; Kawamura et al., 2003). The sediments can therefore be expected to provide a useful archive of the Holocene environment. In order to conduct a paleoceanographic and paleoclimatologic study of the Okhotsk area, such as on the changes in sediment supply from land masses and/or fluctuations in the paleocurrent, it is essential to carry out a lateral examination of the diagenetic effects on the magnetic properties of the sediments. For example, Rey et al. (2005) showed that the extent and mode of early diagenesis are largely controlled by local depositional environments along the Iberian coast. In the southern Okhotsk Sea, Kawamura et al. (2003) demonstrated that the rock magnetic records of two sediment cores were affected by post-depositional diagenesis with regional differences. The aim of this study was to investigate variations in the effects of early diagenesis along a depth transect and to determine the sedimentary factors affecting diagenesis, based on new data from 11 cores recovered from the southern Okhotsk Sea. 


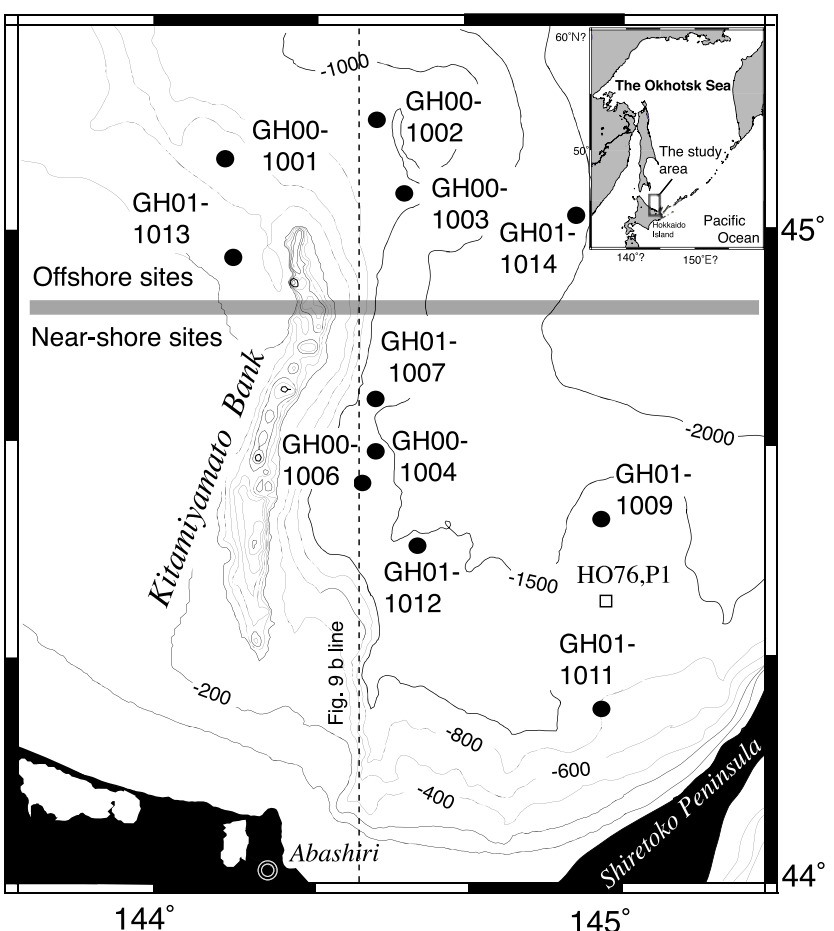

Fig. 1. The Okhotsk Sea and location of core sites. Core sites are subdivided into the offshore sites and the near-shore sites by the gray line at approx. $44.6^{\circ} \mathrm{N}$ (see text). •: this study and $\square$ : reference sites (Kawahata et al., 2003; Shimada et al., 2004).

Table 1. Core Sites.

\begin{tabular}{|c|c|c|c|c|c|c|c|}
\hline Core & Latitude $(\mathrm{N})$ & Longi & tude (E) & $\begin{array}{c}\text { Water } \\
\text { depth(m) }\end{array}$ & $\begin{array}{c}\text { Core } \\
\text { Length }(\mathrm{cm})\end{array}$ & $\begin{array}{c}\text { number of } \\
\text { samples }\end{array}$ & Reference \\
\hline GH00-1001 & $45^{\circ} \quad 5.91$ & $143^{\circ}$ & 39.87 & 461 & 490 & 224 & Kawamura et al. (2003) \\
\hline GH00-1002 & $45^{\circ} \quad 11.00$ & $144^{\circ}$ & 26.98 & 922 & 472 & 216 & This study \\
\hline GH00-1003 & $45^{\circ} \quad 3.54$ & $144^{\circ}$ & 33.69 & 965 & 443 & 211 & This study \\
\hline GH00-1004 & $44^{\circ} 39.50$ & $144^{\circ}$ & 26.98 & 1443 & 440 & 204 & This study \\
\hline GH00-1006 & $44^{\circ} 35.54$ & $144^{\circ}$ & 26.11 & 1348 & 359 & 170 & Kawamura et al. (2003) \\
\hline GH01-1007 & $44^{\circ} \quad 44.00$ & $144^{\circ}$ & 28.02 & 1355 & 468 & 207 & This study \\
\hline GH01-1009 & $44^{\circ} 31.62$ & $144^{\circ}$ & 59.71 & 1214 & 420 & 192 & This study \\
\hline GH01-101 1 & $44^{\circ} \quad 16.51$ & $144^{\circ}$ & 58.50 & 778 & 500 & 228 & This study \\
\hline GH01-1012 & $44^{\circ} 32.01$ & $144^{\circ}$ & 33.19 & 1516 & 403 & 186 & This study \\
\hline GH01-1013 & $44^{\circ} 57.01$ & $144^{\circ}$ & 9.50 & 221 & 343 & 152 & This study \\
\hline GH01-1014 & $45^{\circ} \quad 1.33$ & $144^{\circ}$ & 56.05 & 1739 & 526 & 262 & This study \\
\hline HO76, P1 & $44^{\circ} \quad 32.00$ & $145^{\circ}$ & 1.00 & 760 & 760 & & $\begin{array}{r}\text { Shimada et al. }(2000,2004) \\
\quad \text { Kawahata et al. (2003) }\end{array}$ \\
\hline
\end{tabular}

\section{Core Locations and Sample Descriptions}

Thirteen sediment cores were collected using a 5-m-long gravity corer off the Shiretoko peninsula in the northeastern Hokkaido Island, northeast Japan. The cores were recovered from the area around the Kitamiyamato Bank (Fig. 1) during the R/V "Daini-Hakureimaru" cruises in 2000 and 2001. In the study described here, rock magnetic analysis was performed on nine of the 13 gravity cores recovered (GH00-1002, GH00-1003, GH00-1004, GH01-1007, GH01-1009, GH01-1011, GH01-1012, GH01-1013, and GH01-1014) (Table 1; Fig. 1). Reports on GH00-1001 and GH00-1006 have been published elsewhere (Kawamura et al., 2003), and those data sets are also employed in this paper. The sediment cores were mainly composed of diatomaceous, silty clay having an olive-gray color (Noda et al., 2002). We subdivided the core sites into two areas according to the trend in the total organic carbon (TOC) in the sediments, which will be discussed in the following sections. The core sites between the northern coast-
Table 2. The range of RMTZs based on rock-magnetic parameters.

\begin{tabular}{|c|c|c|c|c|c|}
\hline Near-shore sites & $\begin{array}{c}\text { water } \\
\text { depth (m) }\end{array}$ & Latitude (N) & $\begin{array}{c}\text { RMTZ } \\
\text { length }(\mathrm{cm})\end{array}$ & $\begin{array}{c}\text { upper } \\
\text { boundary }(\mathrm{cm})\end{array}$ & $\begin{array}{c}\text { lower } \\
\text { boundary }(\mathrm{cm})\end{array}$ \\
\hline GH01-1011 & 778 & $44^{\circ} 16.51$ & 120 & 20 & 140 \\
\hline GH01-1009 & 1214 & $44^{\circ} 31.62$ & 40 & 20 & 60 \\
\hline GH01-1007 & 1355 & $44^{\circ} 44.00$ & 120 & 60 & 180 \\
\hline GH00-1004 & 1443 & $44^{\circ} 39.50$ & 150 & 30 & 180 \\
\hline GH00-1006 & 1348 & $44^{\circ} 35.54$ & 70 & 80 & 150 \\
\hline GH01-1012 & 1516 & $44^{\circ} 32.01$ & 60 & 50 & 110 \\
\hline \multicolumn{6}{|l|}{ Offshore sites } \\
\hline GH01-1013 & 221 & $44^{\circ} 57.01$ & 50 & 70 & 120 \\
\hline GH00-1001 & 461 & $45^{\circ} \quad 5.91$ & 230 & 130 & 360 \\
\hline GH00-1002 & 922 & $45^{\circ} 11.00$ & 200 & 40 & 240 \\
\hline GH00-1003 & 965 & $45^{\circ} \quad 3.54$ & 240 & 50 & 290 \\
\hline GH01-1014 & 1739 & $45^{\circ} \quad 1.33$ & 90 & 60 & 150 \\
\hline
\end{tabular}

line of Hokkaido and the $44.60^{\circ} \mathrm{N}$ parallel (bold wide gray line in Fig. 1; samples GH01-1009, GH01-1007, GH001006, GH00-1004, and GH01-1012) will be referred to as the "near-shore sites", and those north of the $44.60^{\circ} \mathrm{N}$ parallel (GH01-1013, GH01-1014, GH00-1003, GH00-1001 and GH00-1002) will be referred to as the "offshore sites". The offshore sites are distributed to the north of the Kitamiyamato Bank (Fig. 1).

All of the cores studied contain a glassy volcanic ash layer in their upper parts (Table 2; Fig. 2). Kawamura et al. (2003) reported that the refractive indexes of the volcanic glass from GH00-1001 $(37 \mathrm{~cm})$ and GH00-1006 (49 $\mathrm{cm}$ ) range from 1.4981 to 1.5035 , and concluded that the volcanic ash layers could be correlated with one of the widespread tephras in Hokkaido, called the Ta-a tephra, which was created by an eruption in 1739 A.D. (Machida and Arai, 2003). It is most likely that the volcanic ash layers present in the upper part of the other cores are also correlated with Ta-a tephra (Fig. 2).

The bottoms of the cores have been dated to $2700 \mathrm{yr}$ B.P. and $2600 \mathrm{yr}$ B.P. for GH00-1006 (359 cm) and GH01-1011 $(500 \mathrm{~cm})$, respectively, by an AMS ${ }^{14} \mathrm{C}$ analytical method based on bulk carbon and molluscan shell samples (Ikehara et al., 2002; Itaki and Ikehara, 2004). The sedimentation rates of GH00-1006 and GH01-1011 are calculated to be $133 \mathrm{~cm} / \mathrm{kyr}$ and $192 \mathrm{~cm} / \mathrm{kyr}$, respectively. Shimada et al. $(2000,2004)$ suggested that the average sedimentation rate in the southern Okhotsk Sea is $100 \mathrm{~cm} / \mathrm{kyr}$ based on the tephrostratigraphy and radiocarbon ages of molluscan shells from core HO 76, P1 (Fig. 1; Table 1). For core GH01-1014, two AMS ${ }^{14} \mathrm{C}$ ages of molluscan shell samples were measured at the Beta Analytic Corporation. The measured age of the sample at $432.5 \mathrm{~cm}$ was $13,080 \pm 150$ yr B.P. (Accession No.: Beta-175425), and the ${ }^{13} \mathrm{C}$ value is $+0.7 \%$. The sample at $434 \mathrm{~cm}$ was dated to $12,880 \pm 150 \mathrm{yr}$ B.P. (Beta-175426), and its ${ }^{13} \mathrm{C}$ value was $+0.9 \%$. Based on these values, the conventional ${ }^{14} \mathrm{C}$ ages are calculated as follows: $13,490 \pm 150 \mathrm{yr}$ B.P. at $432.5 \mathrm{~cm}$ and $13,290 \pm 150$ yr B.P. at $434 \mathrm{~cm}$. There is a slight difference in ages between the upper sample and the lower sample; however, they agree within the range of analytical error. Due to the lack of studies on the reservoir effect in the southern Okhotsk Sea, we did not calibrate for calendar ages in this investigation. The age of 13,390 yr B.P. at a depth of approximately $433 \mathrm{~cm}$ corresponds to a sedimentation rate of $32 \mathrm{~cm} / \mathrm{kyr}$, thereby suggesting that the lower part of core 
Near-shore sites

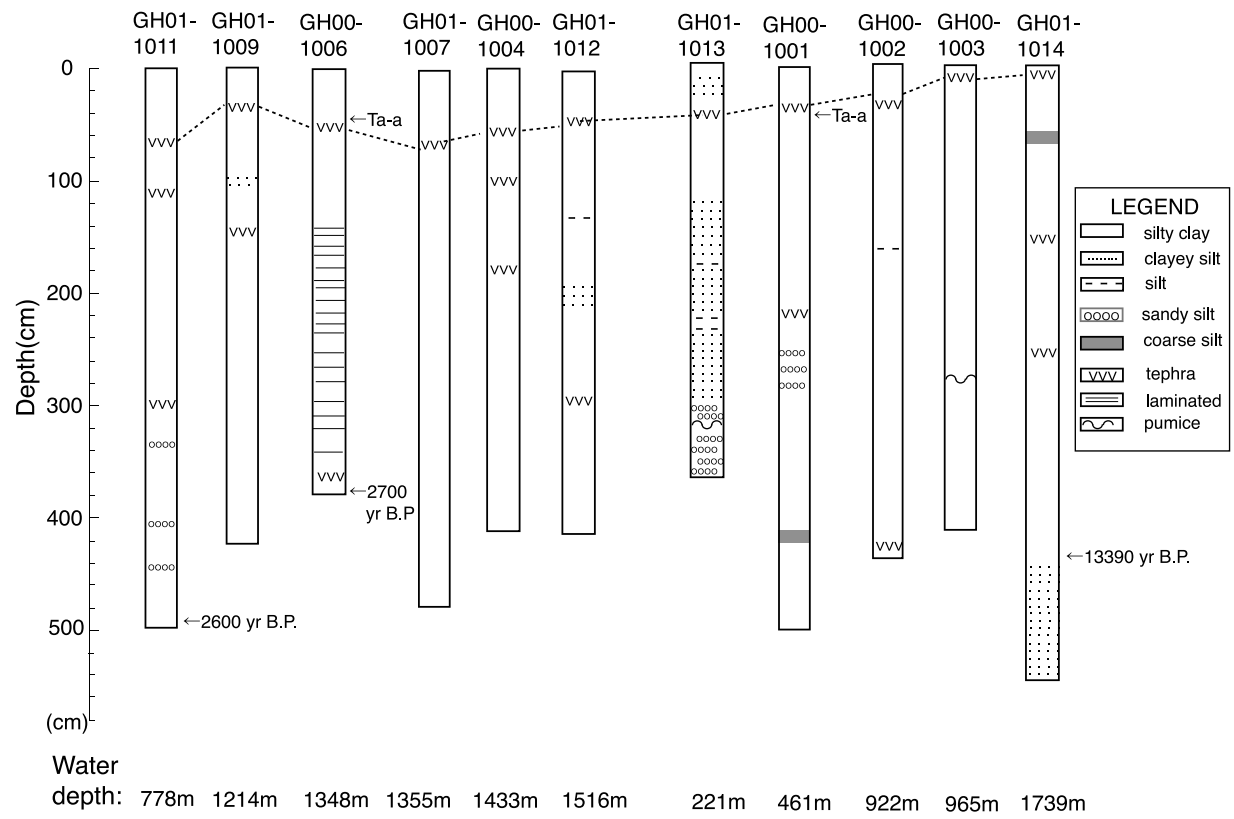

Fig. 2. Lithology of the sediment cores. Horizons of the widespread tephra (Ta-a:1739 A.D.) are shown by a dashed line.

GH01-1014 is older than the Holocene. According to these results, the age of the core bottom may be roughly estimated as 3-10 thousand yr B.P. Attempts to estimate paleomagnetic age based on secular variations has failed to produce meaningful results for any of the studied cores, possibly due to the diagenetic changes in magnetic minerals in the sediment cores, as will be discussed in the following sections. Yamazaki and Oda (2002) also noted that the middle parts of GH00-1002, GH00-1003 and GH00-1004 have been magnetically degraded by the dissolution of magnetic minerals.

\section{Methods}

The sediment cores were sampled using 7-cc plastic cubes at at 2.2-cm intervals for magnetic analysis. Rock magnetic measurements were made on the low-field massspecific magnetic susceptibility $(\chi)$, anhysteretic remanent magnetization (ARM) and isothermal remanent magnetization (IRM) while the specimens were in the wet condition. Measurements of $\chi$ values were made either with a Kappabridge KLY-3S or a Bartington MS2 magnetic susceptibility meter. ARM (for GH00-1001 and GH001002, GH00-1003, GH00-1004, GH00-1006, GH00-1007, GH01-1012, GH01-1013 and GH01-1014) was induced on each sample with a DC biasing field of $0.1 \mathrm{mT}$ in a maximum peak alternating field (AF) of $100 \mathrm{mT}$, at the Okayama University of Science. ARM (for GH01-1009 and GH011011) was imparted with a DC biasing field of $0.1 \mathrm{mT}$ in the maximum peak AF $80 \mathrm{mT}$, at the Japan Agency for MarineEarth Science and Technology. $\chi_{\mathrm{ARM}}$ is calculated by dividing ARM with the steady biasing field. Magnetic grain size is estimated on the basis of $\chi_{\mathrm{ARM}} / \chi$, and this parameter is indicative of the relative proportion of fine-grained magnetic minerals, such as the stable single-domain grains (King et al., 1982). A high $\chi_{\mathrm{ARM}} / \chi$ value implies that the sample is rich in fine-grained magnetite. IRMs were measured with a spinner-magnetometer (Natsuhara-Giken SMM-85, at Okayama University of Science, Kyoto University and the Japan Agency for Marine-Earth Science and Technology). IRMs (2.5 T and $-0.3 \mathrm{~T})$ were induced along one axis of the sample. $\mathrm{S}_{-0.3 \mathrm{~T}}$ and HIRM were calculated according to the definition by Bloemendal et al. (1992):

$$
\begin{gathered}
\mathrm{S}_{-0.3 \mathrm{~T}}=\left(1-\mathrm{IRM}_{-0.3 \mathrm{~T}} / \mathrm{SIRM}\right) / 2, \text { and } \\
\mathrm{HIRM}=\left(\mathrm{SIRM}+\mathrm{IRM}_{-0.3 \mathrm{~T}}\right) / 2 .
\end{gathered}
$$

$\mathrm{S}_{-0.3 \mathrm{~T}}$ reflects the relative proportion of low-coercivity magnetic minerals in a sample, and a high value of $S_{-0.3} \mathrm{~T}$ implies that the sample is rich in magnetite. HIRM indicates the absolute concentration of high-coercivity material, and so a high HIRM indicates a sample rich in high-coercivity minerals, such as hematite and goethite. After measurements of $\chi$ had been made, ARM, and SIRM were measured: the samples were either oven-dried at $40^{\circ} \mathrm{C}$ or freezedried overnight and then weighed to calculate the dry-based mass-specific magnetic parameters.

Temperature-dependent magnetic properties, IRM acquisition curves and thermal demagnetization of composite three-axis IRMs were performed. Approximately $50 \mathrm{mg}$ of dried sediments were taken from the discrete samples and wrapped in plastic film to prepare a specimen. IRM was imparted at $5 \mathrm{~K}$ in a $1.0 \mathrm{~T}$ DC field, and the change in IRM was then measured continuously in steps of 1 degree up to 300 K using a Quantum Design MPMS-2. High-temperature properties were measured using a thermomagnetic balance (Eiko Electric). A separate 50-mg fraction of dried sediments was heated from room temperature to $600^{\circ} \mathrm{C}$ and cooled in air at a rate of about $8^{\circ} \mathrm{C} / \mathrm{min}$ in an applied field of $0.75 \mathrm{~T}$. The magnetic phase transitions, such as the Curie point and the Verwey transition, were diagnosed for magnetic mineralogy. IRM acquisition curves were obtained 
Near-shore sites

GH01-1011 (water depth=778 m)

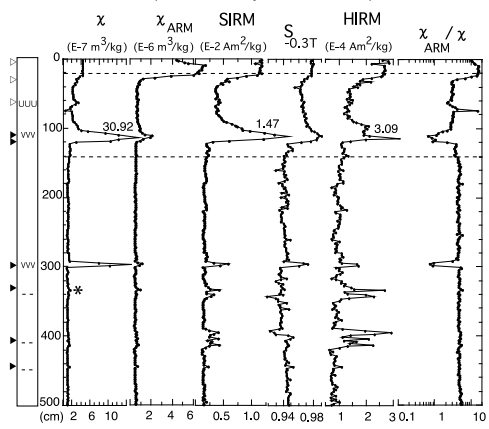

GH01-1007 (=1355 m)

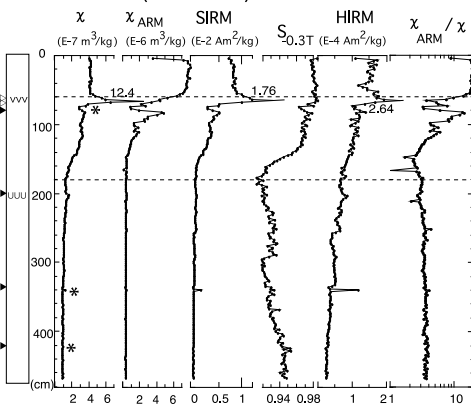

GH01-1009 (=1214 m)

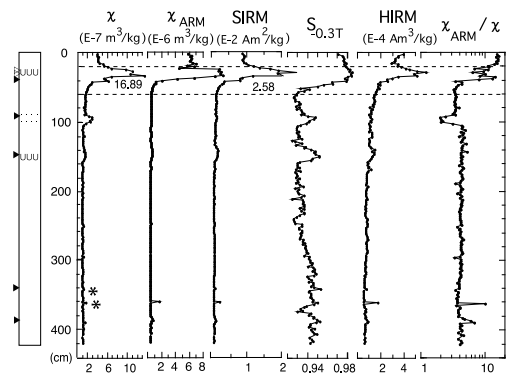

GH00-1004 (=1443 m)

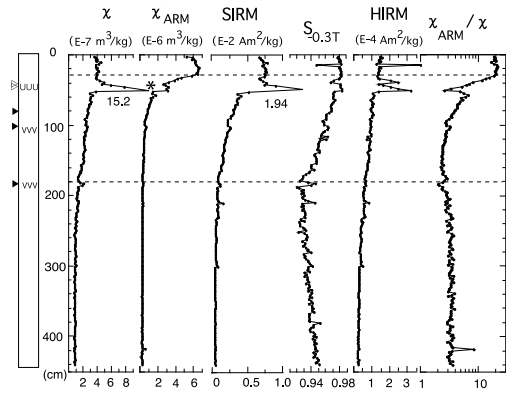

GH00-1006 (=1348 m)

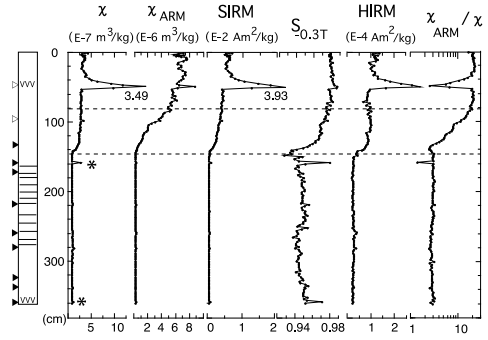

GH01-1012 (=1516 m)

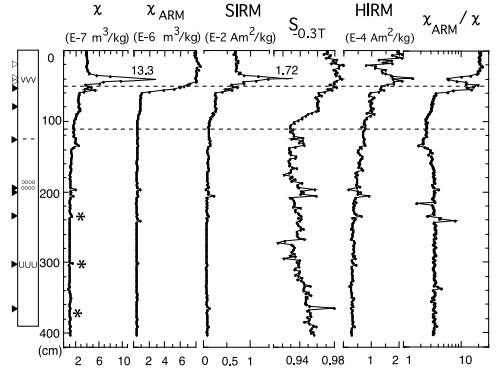

$\triangleright$ no FP

* with basaltic rock

Fig. 3. Downcore plots of rock-magnetic parameters for GH01-1011, GH01-1009, GH01-1007, GH00-1006, GH01-1004 and GH01-1012. From left to right-lithology; $\chi$ : low-field magnetic susceptibility $\left(\mathrm{m}^{3} / \mathrm{kg}\right) ; \chi_{\mathrm{ARM}}$ : susceptibility of $\mathrm{ARM}\left(\mathrm{m}^{3} / \mathrm{kg}\right) ; \mathrm{SIRM}\left(\mathrm{Am}{ }^{2} / \mathrm{kg}\right) ; \mathrm{S}_{-0.3 \mathrm{~T}} ; \mathrm{HIRM}\left(\mathrm{Am}{ }^{2} / \mathrm{kg}\right)$; $\chi_{\mathrm{ARM}} / \chi$. Triangles indicate microscopically investigated horizons—open symbols: no framboidal pyrite (FP); solid symbols: with FP. *: with basaltic rocks. Plots for GH00-1006 are reproduced from Kawamura et al. (2003).

for several selected samples from GH00-1004 to investigate the coercivity distribution of magnetic minerals using the Quantum Design MPMS XL5. IRMs were imparted in the vertical direction, and the magnetizations were measured in 64-70 steps from $1 \mathrm{mT}$ up to $5 \mathrm{~T}$ at $300 \mathrm{~K}$. The IRM acquisition curves were analyzed by the method proposed by Egli (2003), following which they were plotted on a logarithmic field scale, converted to the gradient curve and fitted with skewed generalized Gaussian (SGG) functions, in which skewness and kurtosis are introduced for each population in addition to the median destructive field (MDF) and dispersion parameter. The SGG functions are capable of fitting distorted distributions that may have been produced by thermal activation, magnetic interaction (Heslop et al., 2004) and/or other unidentified causes in the geological process. Another advantage of this method is that the measurement error is reduced by progressive transformation in the magnetization and the field axes and also by low-pass filtering. Composite IRMs acquired parallel to the three orthogonal axes of each specimen (hard component: $0.3-$ 2.5 T; medium: $0.1-0.3 \mathrm{~T}$; soft: $0-0.1 \mathrm{~T})$ were subjected to stepwise thermal demagnetization (Lowrie, 1990) with a model MMTD1 thermal demagnetizer (Magnetic Measurements Co.) and measured with a superconducting rock magnetometer (2G model 760). Magnetic susceptibility was measured using a Bartington MS2 magnetic susceptibility meter.

In addition to carrying out the above magnetic experiments on the samples, those samples with magnetically re- markable features were wet-sieved through a $63-\mu \mathrm{m}$ mesh opening, and the residues were observed under an optical microscope. These horizons are presented in Figs. 3 and 4.

\section{Results}

4.1 Downcore variations in rock magnetic parameters

The rock magnetic parameters and lithologic columns are shown in Figs. 3 and 4. Common features are observed in the rock magnetic parameters for all sites: (1) prominent peaks associated with episodic changes in lithology and (2) a rapid but smooth downward decrease in the rock magnetic parameters. The rock magnetic results of GH00-1004 and GH00-1002 will be described below as typical examples of samples from near-shore and offshore sites, respectively (Fig. 1).

4.1.1 GH00-1004 The prominent peaks of $\chi$, SIRM and HIRM and the negative peaks of $\chi_{\mathrm{ARM}} / \chi$ are found at approximately $50 \mathrm{~cm}$. A high concentration of volcanic glass shards was observed under the optical microscope in the sample taken from this level. Volcanic glass shards were also observable at levels corresponding to the small peaks at $101 \mathrm{~cm}$ and $183 \mathrm{~cm}$. We also found basaltic granules from the sample at $48 \mathrm{~cm}$. The sample containing basaltic rock displayed a high value of $\chi, \chi_{\text {ARM }}$, SIRM and $S_{-0.3}$, reflecting the generally acknowledged fact that basaltic rocks are abundant in magnetite $\left(\mathrm{Fe}_{3} \mathrm{O}_{4}\right)$ (e.g., Hunt et al., 1995).

Except for the large peaks of highly magnetic materials of volcanic origin at $50 \mathrm{~cm}$, the highest value of $\chi-$ $3.8 \times 10^{-7} \mathrm{~m}^{3} / \mathrm{kg}$ - is in the upper part of the core. The $\chi$ 
GH01-1013 (water depth=221 m)

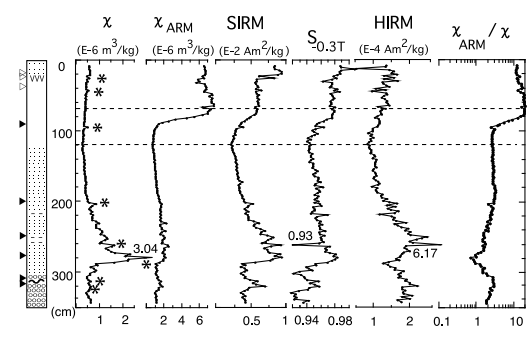

$\mathrm{GH} 00-1003$ (=965 m)

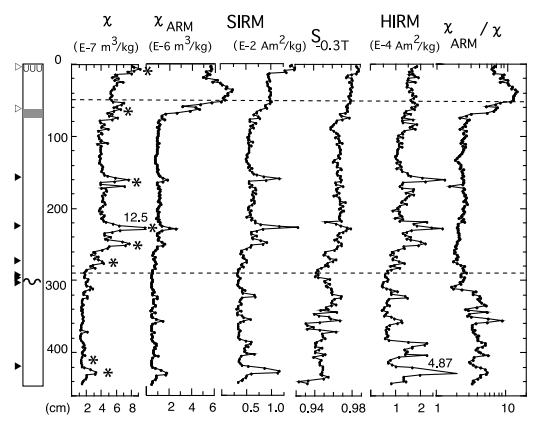

GH00-1001 (=461 m)

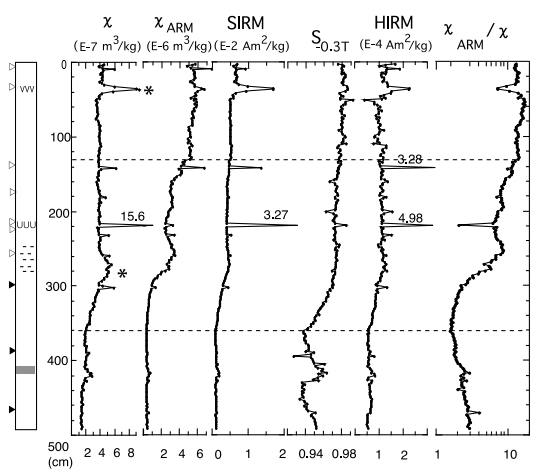

GH00-1002 (=922 m)

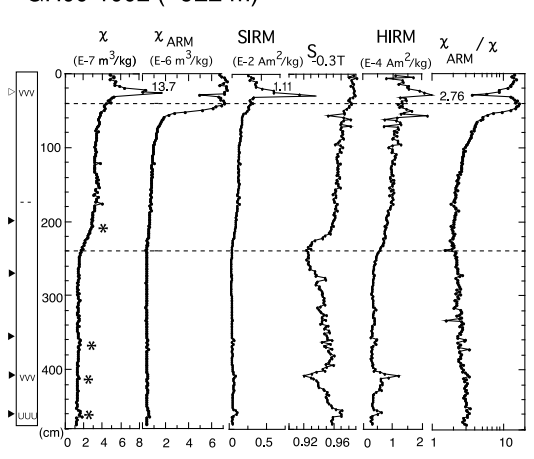

GH01-1014 (=1739 m)

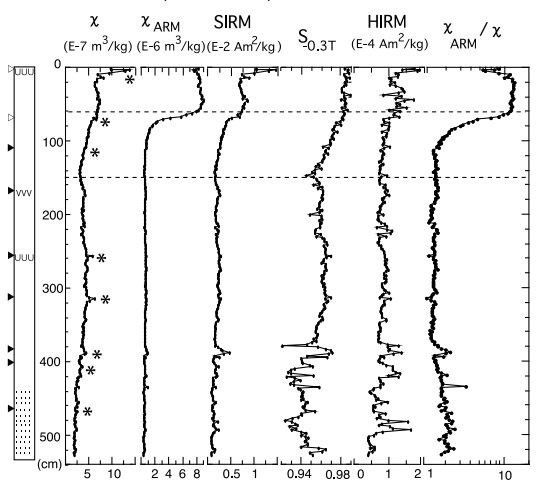

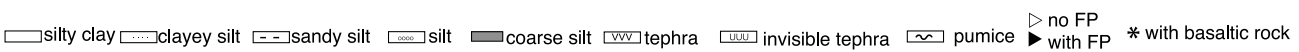

Fig. 4. Downcore plots of various parameters for GH00-1001, GH01-1013, GH00-1002, GH00-1003 and GH01-1014. See Fig. 3 for explanations. Plots for GH00-1001 are reproduced from Kawamura et al. (2003).

value starts to decrease at about $30 \mathrm{~cm}$ and falls to a nearly constant value of $1.3 \times 10^{-7} \mathrm{~m}^{3} / \mathrm{kg}$ below $180 \mathrm{~cm}$, which is $34 \%$ of the mean value found in the upper part of the core. $\chi_{\text {ARM }}$ displays the highest value $-7.5 \times 10^{-6} \mathrm{~m}^{3} / \mathrm{kg}$-in the upper part of the core and also starts to decrease at about $30 \mathrm{~cm}$; it also stabilizes at its lowest value below $180 \mathrm{~cm}$, at a value approximately $5 \%$ of that observed at the upper part of the core. The highest value of SIRM-7.2 $\times 10^{-3}$ $\mathrm{Am}^{2} / \mathrm{kg}$ - is found in the upper part, and it quickly starts to decrease at about $20 \mathrm{~cm}$, reaching its minimum level of $0.8 \times 10^{-3} \mathrm{Am}^{2} / \mathrm{kg}$ below $190 \mathrm{~cm}$, where it retains $9 \%$ of the initial IRM value. $S_{-0.3} \mathrm{~T}$ is initially 0.98 ; it then starts to decrease at $30 \mathrm{~cm}$ and falls to 0.93 at about $180 \mathrm{~cm}$, where it converts to an increasing trend towards the bottom, ultimately recovering to 0.95 . The highest value of HIRM$1.4 \times 10^{-4} \mathrm{Am}^{2} / \mathrm{kg}$ - occurs at the upper part of the core, and it also starts to decrease at $30 \mathrm{~cm}$. It gradually decreases towards the bottom of core. The magnetic granulometric index, $\chi_{\mathrm{ARM}} / \chi$, starts to decrease at $30 \mathrm{~cm}$ and displays an almost constant value below $180 \mathrm{~cm}$. All of the magnetic parameters start to rapidly decrease at $20-30 \mathrm{~cm}$ and drop to their minimum values at $180 \mathrm{~cm}$. Large decreases in the concentration-dependent rock magnetic parameters (as represented by the plot for $\chi_{\mathrm{ARM}}$ ) are all confined to the 30 - to $180-\mathrm{cm}$ level. It should be noted that large clusters $(>63$ $\mu \mathrm{m})$ of framboidal pyrite $\left(\mathrm{FeS}_{2}\right)$ were found below $111 \mathrm{~cm}$ (Fig. 3).
4.1.2 GH00-1002 Downcore variations of rock magnetic parameters are shown in Fig. 4. Large peaks of $\chi$ and SIRM are found at $29 \mathrm{~cm}$ where a volcanic ash layer is also observed. Clear negative peaks of $\chi_{\text {ARM }}$ and $\chi_{\text {ARM }} / \chi$ are present, as in the case for site GH00-1004. Peaks of $\chi$ and SIRM are found at $410 \mathrm{~cm}$ and $463 \mathrm{~cm}$. A negative peak of $\mathrm{S}_{-0.3 \mathrm{~T}}$ is found at $463 \mathrm{~cm}$. Volcanic glass shards were found from the sample at $463 \mathrm{~cm}$. Peaks of $\chi$ and SIRM, which are found at approximately $175 \mathrm{~cm}$, may be attributed to the distribution of a sandy silt layer. We found basaltic granules from the samples at 201, 358, 410 and 463 $\mathrm{cm}$, which correspond to the levels displaying small peaks of HIRM.

Above $40 \mathrm{~cm}, \chi$ displays values higher than $1.4 \times 10^{-7}$ $\mathrm{m}^{3} / \mathrm{kg}$; it then starts to decrease between $40 \mathrm{~cm}$ and 220 $\mathrm{cm}$, falling to $30 \%$ of the initial value below $240 \mathrm{~cm} . \chi_{\text {ARM }}$, SIRM and HIRM also display trends similar to $\chi$, with the respective values falling to 5,7 , and $34 \%$ of the initial values. $S_{-0.3} \mathrm{~T}$ starts to increase below $240 \mathrm{~cm}$. The upper limit of the occurrence of framboidal pyrite was at $201 \mathrm{~cm}$.

\subsection{Magnetic mineralogy}

The results of the temperature dependency of magnetization, the IRM acquisition curve, and the thermal demagnetization of composite IRMs are shown in Figs. 5, 6 and 7. The samples were selected from the sediments above, within and below the RMTZ (Rock Magnetic Transition Zone: see Section 5.1 for explanation) from GH00-1004 and GH00-1006 (the near-shore sites) and from GH00-1001 
above RMTZ
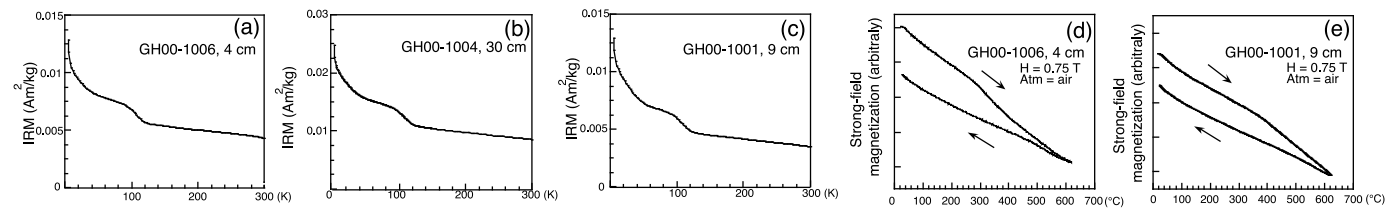

RMTZ
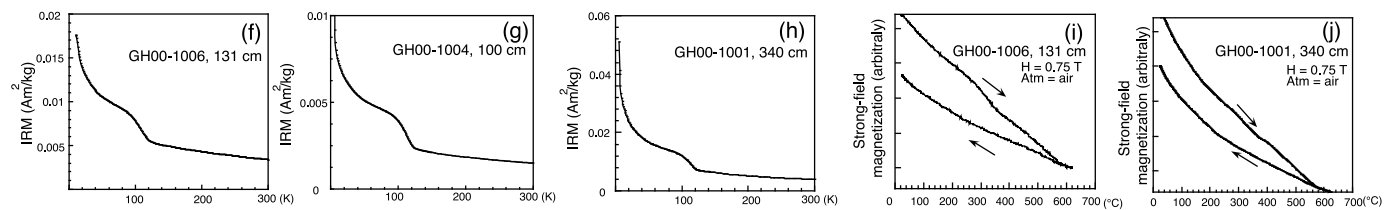

below RMTZ
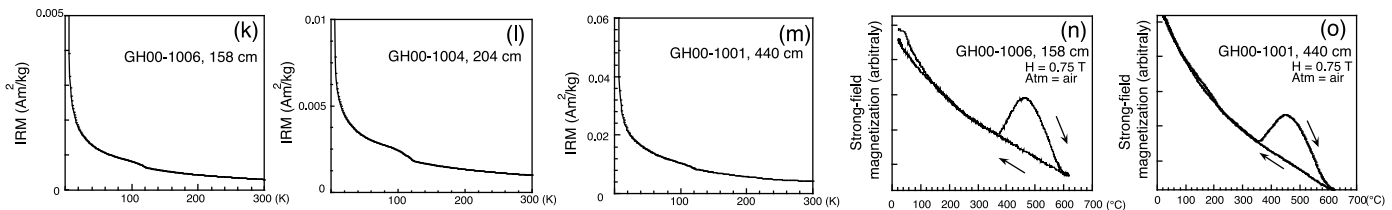

Fig. 5. Thermal demagnetization curves of low-temperature IRM and thermomagnetic curves. The samples were selected from near-shore sites (GH00-1006 and GH00-1004), and offshore site (GH00-1001).

(a) above RMTZ, GH00-1004, $19 \mathrm{~cm}$
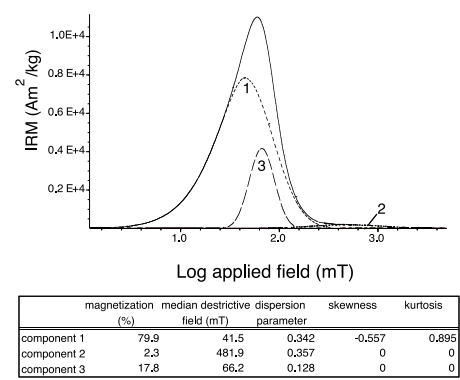

(b) in RMTZ, GH00-1004, $125 \mathrm{~cm}$
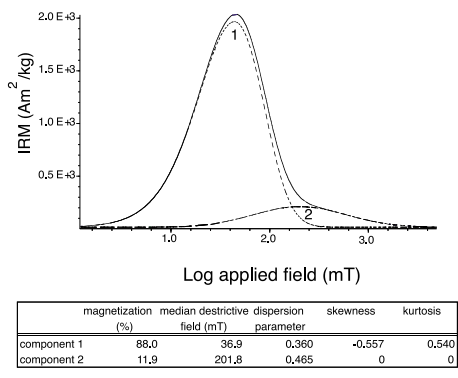

(c) below RMTZ, GH00-1004, $204 \mathrm{~cm}$
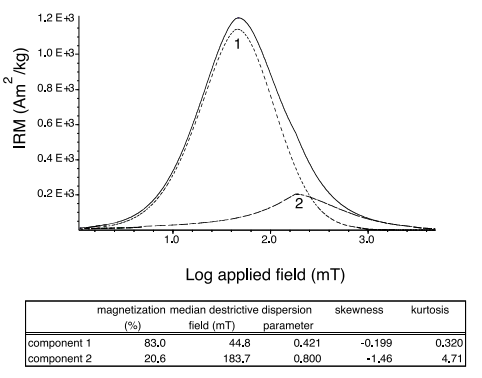

Fig. 6. The results of IRM analysis performed with the method of Egli (2003). The solid line shows the distribution of MDF for bulk IRM. The dashed lines show decomposed components. Contribution, MDF, dispersion, skewness, and kurtosis of each component are also indicated for each sample.

(the offshore sites).

The Verwey transition (at $120 \mathrm{~K}$ ) is evident in Fig. 5(a)(c). The transitions are significantly smeared towards lower temperatures, which is indicative of the occurrence of maghemitization (Özdermir et al., 1993). The Curie point of magnetite is not clearly defined (Figs. 5(d), (e)), and only a slight deflection in the heating curve is observed at about $350^{\circ} \mathrm{C}$ (Fig. 5(d)).

Three MDF components are shown in Fig. 6(a). The MDF of the first component is $42 \mathrm{mT}$ and corresponds to $80 \%$ of the total moment. The second component is minor in terms of contribution $(2 \%)$, but it does show a very high MDF (480 mT). This component may possibly be borne by hematite $\left(\alpha \mathrm{Fe}_{2} \mathrm{O}_{3}\right)$. The third component has relatively high coercivity $(66 \mathrm{mT})$ and a very narrow dispersion parameter $(0.128)$. Components with very narrow dispersion (slightly above 0.1 ) are believed to be of biogenic origin, since magnetosome are known to have narrow size ranges (Kruiver and Passier, 2001: Egli, 2004). Thermal demagnetization of composite IRMs supports the presence of magnetite and hematite. The soft component
(Fig. 7(a)) displays an unblocking temperature of approximately $600^{\circ} \mathrm{C}$, and there is also a slight change in the slope at approximately $300^{\circ} \mathrm{C}$. The medium and high coercivity components show unblocking temperatures at approximately $600^{\circ} \mathrm{C}$ and $700^{\circ} \mathrm{C}$, respectively. These results point to the presence of slightly oxidized magnetite, biogenic magnetite and also minor amounts of hematite above the RMTZ.

For the samples within the RMTZs, the low-temperature IRM curves clearly show Verwey transitions (Fig. 5 (f), (h)). The Curie point of magnetite $\left(580^{\circ} \mathrm{C}\right)$ is also distinctly observable on the heating curves (Fig. 5(i), (j)). The IRM analysis reveals two contrasting components (Fig. 6(b)) one having moderate MDF (37 mT) and the other having high MDF (202 mT). We conclude that the former is borne by detrital magnetite and the latter by hematite. It should be noted that about $12 \%$ of the remanence is carried by hematite in this sample. Since the SIRM of hematite is less than $1 \%$ that of magnetite, a considerable amount of hematite is believed to be present in the sample. The results of thermal demagnetization of composite IRMs also support 

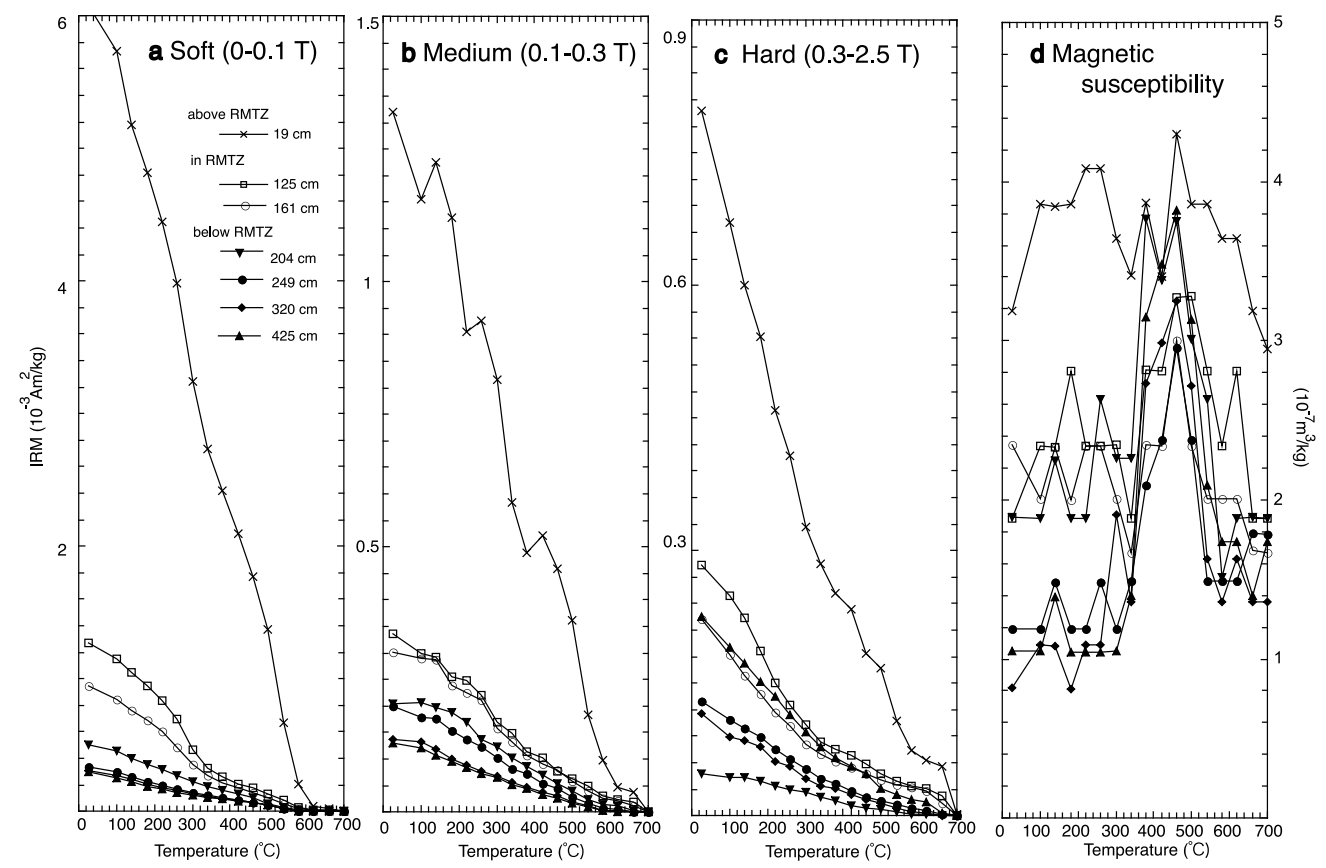

Fig. 7. Stepwise thermal demagnetization of composite three-axis IRMs. (a) The soft component correspond to the coercivity spectrum (0-0.1 T), (b) medium (0.1-0.3 T), (c) hard (0.3-2.5 T) and (d) magnetic susceptibility measured after each step of heating.

the presence of two magnetic components. The soft component is unblocked at $580^{\circ} \mathrm{C}$, whereas the medium and hard components survive up to $680^{\circ} \mathrm{C}$ (Fig. 7). The unblocking curves also indicate the presence of a third magnetic mineral that loses a substantial portion of its remanence in the soft, medium and even hard IRM curves at about $300^{\circ} \mathrm{C}$ (Fig. 7(b)).

As in the upper sediments, magnetite and hematite are also recognized in samples below the RMTZs. However, the concentrations of these magnetic minerals seem to be significantly reduced. The Verwey transition is only barely observable. The presence of magnetic minerals can no longer be inferred from the thermomagnetic curves upon heating. Only artificial formations of magnetite during heating are indicated by the large hump in the heating curve (Figs. 5(n), (o); 7(d)). An abundance of pyrites in the sediments may play a major role in the production of magnetite by heating at temperatures above $300^{\circ} \mathrm{C}$ (Roberts and Pillans, 1993). IRM analysis shows results similar to those of samples from the RMTZs (MDF are $45 \mathrm{mT}$ and $180 \mathrm{mT}$; Fig. 6(c)); however, in samples below the RMTZs, remanence borne by hematite is much higher $(21 \%)$. The thermal demagnetization of composite IRMs also supports the magnetic mineralogy inferred above.

\section{Discussion}

\subsection{Rock magnetic transition zone (RMTZ)}

In all cores, the $\chi, \chi_{\text {ARM }}, S I R M$ and $S_{-0.3 \mathrm{~T}}$ values start to decrease with depth, falling to their minimum values in the middle parts (Figs. 3 and 4). These zones are shown in Table 2, and their boundaries are represented by dashed lines in Figs. 3 and 4. The upper boundaries were defined to be where the (ARM values start to decrease, and the lower boundaries were determined to be where the $S_{-0.3} \mathrm{~T}$ values fall to their minimum. We define this depth zone as the "rock magnetic transition zone (RMTZ)" in this paper. The RMTZ of GH00-1004 is narrower than that of GH00-1002. The lower boundaries of RMTZ tend to be deeper in cores from the offshore sites than in those of the near-shore sites, with the expection of GH01-1013 and GH01-1014.

There is a clear difference in the values of concentrationdependent rock magnetic parameters, such as $\chi, \chi_{\text {ARM }}$ and SIRM, above and below the RMTZ. Most of the concentration-dependent rock magnetic parameters below the RMTZ are reduced to $47-93 \%$ of their respective values above the zone. The core sediments studied here are mostly composed of homogeneous silty clay, with the exception of the occasional thin streaks of relatively coarser sediments. The only notable exception is GH01-1013, whose lower half is composed of clayey silt (Fig. 4). Thus, the systematic difference between the rock magnetic parameters cannot be attributed to lithological differences between the upper and lower sediments, and we believe the cause lies in early diagenetic effects.

Within the RMTZ, the $\chi, \chi_{\text {ARM }}$ and SIRM curves display smooth and quick drops in intensity, implying reductions in magnetic minerals within this zone (Figs. 3 and 4). The granulometric parameter, $\chi_{\mathrm{ARM}} / \chi$, also decreases rapidly in the upper part of the RMTZ, implying the depletion of finegrained magnetic minerals or, in other words, the selective dissolution of superparamagnetic and single-domain-sized magnetite in the RMTZ. The $\mathrm{S}_{-0.3 \mathrm{~T}}$ value also decreases in this zone, which is indicative of the selective dissolution of magnetite compared to hematite. Based on these results, we conclude that the fine-grained magnetic minerals in the sediments have been quickly dissolved in the RMTZ by the effects of early diagenesis. The extremely small rise in the $\mathrm{S}_{-0.3 \mathrm{~T}}$ curve below the RMTZ may indicate the dissolution of a high-coercivity magnetic mineral, which in this case is hematite. The slight increase in $\chi_{\mathrm{ARM}} / \chi$ toward the core 


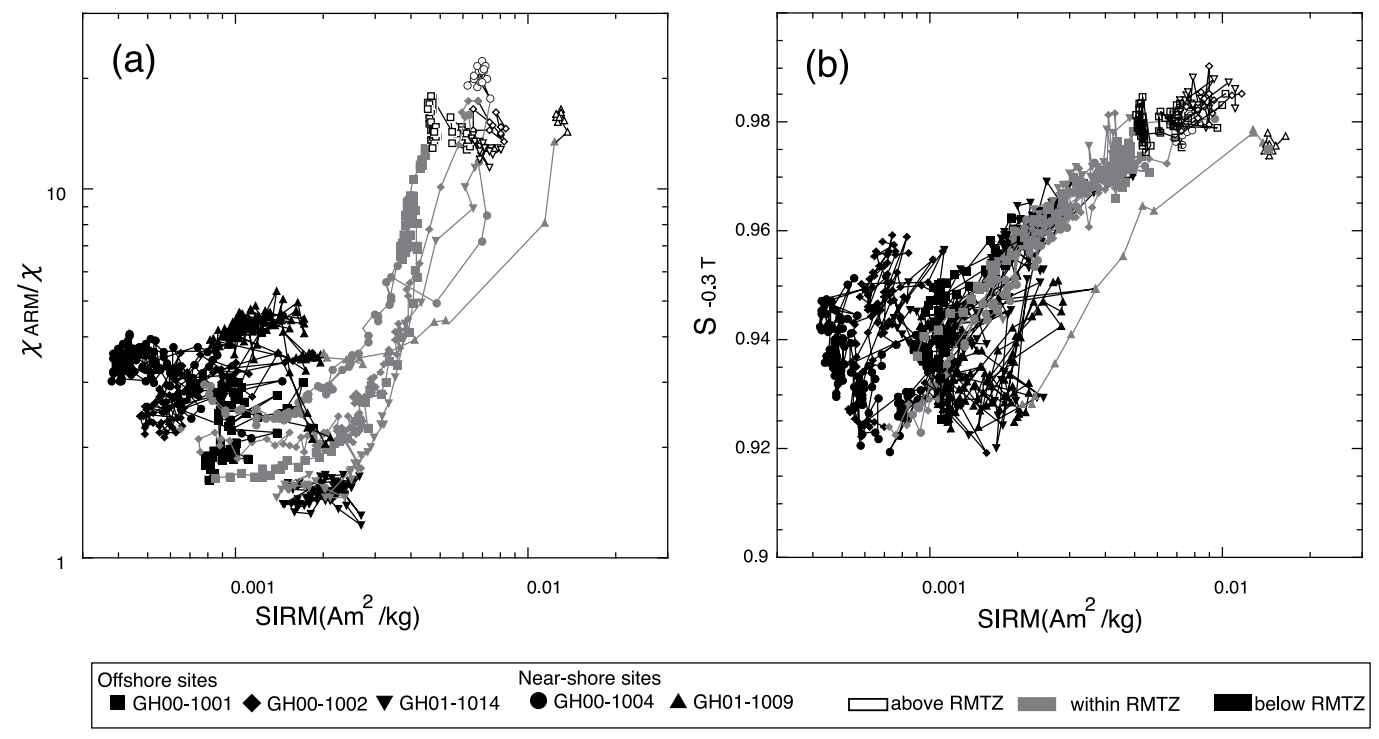

Fig. 8. Biplots of rock magnetic parameters. (a) SIRM vs. $\chi_{\text {ARM }} / \chi$ and (b) SIRM vs. $S_{-0.3}$ T. The peak data caused by volcanic ash layers were deleted. See text for details.

bottom may also indicate a gradual decrease in mean grain size due to the progressive dissolution of the surviving magnetite and hematite grains (Figs. 3 and 4). Such reductions in rock magnetic parameters have been widely recognized in marine sediments and have been attributed to early diagenesis (e.g., Leslie et al., 1990a, b; Bloemendal et al., 1993; Yamazaki et al., 2003; Liu et al., 2004; Rey et al., 2005).

\subsection{Dissolution of magnetic minerals}

The downcore change in the composition of the magnetic minerals may be understood as the result of the dissolution of primary minerals (e.g., Hilgenfeldt, 2000) and the formation of authigenic minerals (e.g., Liu et al., 2004). Consequently, we discuss the environment in the sediments which accelerate the dissolution and formation processes of magnetic minerals in this section.

Framboidal pyrite, which is indicative of sulfate reduction and the subsequent replacement of magnetite with pyrite (e.g., Berner, 1980; Passier and Dekkers, 2002), is always present in the RMTZ (Figs. 3, 4 and 7). The detailed organic carbon content and element constitution data have been reported by Komori et al. $(2001,2002)$ only for GH00-1006 and GH01-1011. Their studies showed that the samples had a relatively high total carbon content of $2.06-1.60 \mathrm{wt} \%$ in the 0 - to $150-\mathrm{cm}$ section of GH00-1006 and $2.29-1.93 \mathrm{wt} \%$ in the 0 - to $130-\mathrm{cm}$ section of GH011011. The content of organic carbon gradually decreases, reaching its lowest level at the core bottoms. These observations suggest that the dissolution of organic carbon had occurred within the RMTZ together with the crystallization of pyrite because the thermal demagnetization curves of composite IRMs show unblocking temperatures at approximately $300^{\circ} \mathrm{C}$ (Fig. 7). If such a medium unblocking temperature was caused by the presence of greigite, the dissolved iron ions were first transformed into greigite $\left(\mathrm{Fe}_{3} \mathrm{~S}_{4}\right)$ under anoxic conditions before they took the final form of pyrite. However, there may be other possible explanations for the medium unblocking temperature.

Magnetite was recognized in the sediments; however, its volume and grain size varies (Figs. 6(a); 5(a)-(e)). The shape of the Verwey transition (Figs. 5(f)-(h)) is much more pronounced compared to the curves in Figs. 5(a)-(c), suggesting that magnetite covered with maghemite $\left(\gamma \mathrm{Fe}_{2} \mathrm{O}_{3}\right)$ is dissolved within the RMTZ. A similar phenomenon has been reported in previous studies (Torii, 1997; Yamazaki et al., 2003). It is believed that the oxidized rind of magnetite is dissolved as it passes through the iron redox boundary (suboxic zone) in the sediments during early diagenesis. Hematite was also recognized in the sediments. However, the decrease in the HIRM values downward suggests that hematite is dissolved and its volume decreases. Much of the surviving magnetite and hematite start to dissolve within the RMTZ.

5.3 Geographic variations of diagenetic modifications

The top and bottom depths of the RMTZ vary from core to core (Table 2). The thicknesses of RMTZ are different among sites. The top of RMTZ is defined at $20 \mathrm{~cm}$ for GH01-1011 and at $130 \mathrm{~cm}$ for GH00-1001. These facts suggest that the sedimentary environments of the core sites may contribute to the differences in the thickness of the RMTZ created during early diagenesis.

For further comparison, we have selected five sitesGH00-1001, GH00-1002 and GH01-1014 from the offshore sites and GH00-1004 and GH01-1009 from the near-shore sites. Downcore variations in magnetic mineral concentrations $(\mathrm{SIRM})$ and magnetic grain size $\left(\chi_{\mathrm{ARM}} / \chi\right)$ are shown in Fig. 8(a). The data above the RMTZ are plotted on the middle-to-upper parts of the graph; the data points for the interval below the RMTZ samples of all sites are plotted from the upper right to the lower left corner of the graph. This biplot diagram simply indicates that the concentrations of magnetic minerals decrease downcore while the size of the magnetic grain increases. This provides evidence supporting the progressive dissolution of magnetic minerals in the downcore direction, with preferential dissolution of finer-grained magnetic minerals. The sediments of GH01-1009 above the RMTZ display relatively high val- 
ues of SIRM, which can be interpreted to be a result of a larger supply of magnetic minerals to the GH00-1009 site from Hokkaido. The sediments of GH00-1004 show relatively high values of $\chi_{\mathrm{ARM}} / \chi$, while the others are not as pronounced. Grain-size analysis of surface sediments has revealed that silty clay is distributed around GHOO1004, while silty clay mixed with clayey silts are distributed around the other cores sites (Ikehara et al., 2001; Noda et al., 2002; Tanabe and Sakamoto, 2002). The results of magnetic grain-size distribution analysis above the RMTZ are consistent with core lithologies. Figure $8(\mathrm{~b})$ is a biplot of SIRM versus $S_{-0.3}$ T. The data points for samples above the RMTZ are plotted on the upper-right section of the graph, while those for samples within the RMTZ are plotted from the upper right to the lower left corner of the graph. The data points for below the RMTZ, however, are plotted in the left-hand region in the graph. This complex distribution may be interpreted in terms of a reduction in low-coercivity minerals within the RMTZ and their restoration below the zone. Although both SIRM and $S_{-0.3} \mathrm{~T}$ decrease rapidly in GH01-1009, more gradual changes are observed in the remaining cores.

Figure 9(a) shows the correlation between the depth range of the RMTZ and the distance from the coast of Hokkaido for each core site (represented by their latitudes). Figure 9(b) shows the bathymetry and core sites along $144^{\circ} 27^{\prime} \mathrm{E}$ (Fig. 1). The upper boundaries of the RMTZ show a slight deepening in the offshore direction, but the correlation is not significant, as indicated by the poor correlation coefficient $(R=0.379)$. A steep offward inclination is observed in the depths of the lower boundaries of the RMTZ, with a significantly higher correlation coefficient $(R=0.747)$, as shown in Fig. 9(a). A diagenetic reduction of magnetic minerals seems to have taken place much more effectively in the near-shore sites than in the offshore ones.

Berner (1980) suggested that diagenetic effect is controlled by the activity of bacteria, which in turn are affected by factors such as dissolved oxygen (DO), temperature and/or organic materials in the sediments. The surface sediments have stable temperatures (between 0 and $3^{\circ} \mathrm{C}$ ) in the study area, and the DO values have been reported to be $0.1-3.0 \mathrm{mg} / \mathrm{l}$ in near-shore sites and $6-8 \mathrm{mg} / \mathrm{l}$ in off-shore sites (Katayama et al., 2002; Takizawa, 1982). Horiuchi and Fukushima (2002) reported that the TOC of the surface sediments decreases northward $\left(44^{\circ} 16^{\prime} \mathrm{N}\right.$ to $\left.44^{\circ} 60^{\prime} \mathrm{N}\right)$ from 1.9 to $1.5 \mathrm{wt} \%$ along the $144^{\circ} 52^{\prime} \mathrm{E}$ meridian. The TOC data for GH01-1011 (near-shore site) and GH01-1014 (offshore site) have been reported by Komori et al. (2002, 2004). The average TOC in GH01-1011 is $1.5 \mathrm{wt} \%$ above $140 \mathrm{~cm}$, and it decreases to $1.1 \mathrm{wt} \%$ below the RMTZ. In GH01-1014, the upper part of the core displays a relatively high TOC value (1.3 wt \%); however, the TOC gradually decreases and falls to $0.9 \mathrm{wt} \%$ at $320 \mathrm{~cm}$. The TOC content continues to decrease towards the core bottom, where it reaches 0.6 wt $\%$. These observations suggest that TOC is consumed by bacterial activity in the sediments and is reduced below the RMTZ. Komori et al. (2002) also noted that the offshore sediments have lower TOC contents than the nearshore sediments. Higher TOC contents accelerate the pyritization process by enhancing the bacterial reduction of ferric

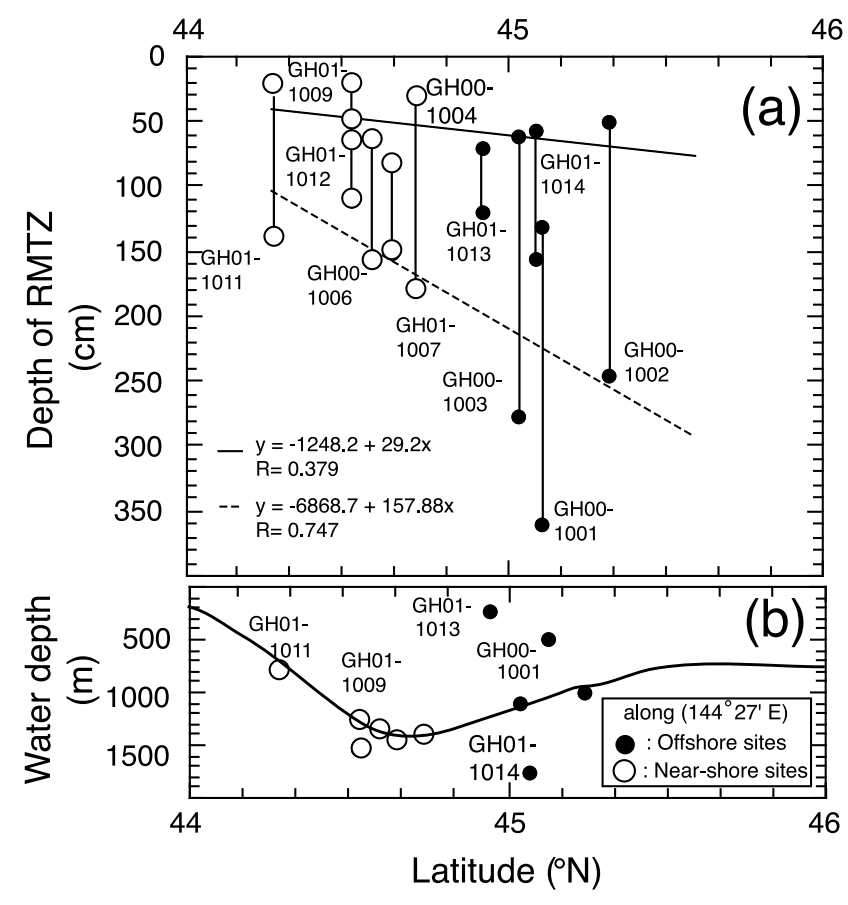

Fig. 9. The relationship between the depth of RMTZ and distance of each core site from the coast of Hokkaido. (a) Upper and lower boundaries of RMTZ are shown by either open circles (near shore sites) or solid circles (offshore sites). Solid and dashed lines indicate the regression line for the upper boundary and lower boundary of RMTZ, respectively. (b) Bathymetry along the line of $144^{\circ} 27^{\prime} \mathrm{E}$ (dashed line in Fig. 1) and core sites.

ion and result in the dissolution of magnetite in marine sediments (e.g., Berner 1980; Canfield and Berner 1987; Rey et al., 2005). Hilgenfeldt (2000) suggested that the degree of the remanence reduction in core sediments due to the dissolution of magnetite is proportional to the amount of organic matter on the sea floor, which is associated with the establishment of anoxic conditions. This is consistent with the presence of anoxic sedimentary conditions at the nearshore sites inferred by our study. Unfortunately, the lack of a detailed age model for each core prevents any further discussions from being made on the effects of sedimentation rate on the diagenetic alterations of magnetic properties of sediments. The TOC content is definitely one of the controlling factors for the depth of the RMTZ in this area.

\section{Conclusions}

Eleven gravity cores were collected from the southern Okhotsk Sea and rock-magnetically analyzed. The following conclusions were drawn on the basis of the results.

1. Peaks in the curves of rock magnetic parameters are produced by the presence of volcanic ashes, basaltic granules and/or relatively coarser detrital grains, implying episodic inputs of magnetic minerals.

2. The rock magnetic transition zones (RMTZs) have been identified in all of the studied cores based on the characteristically decreasing pattern of the concentrationdependent rock magnetic parameters $\left(\chi, \chi_{\text {ARM }}\right.$, and SIRM). These parameters display smooth and rapidly decreasing patterns downcore, suggesting a considerable decrease in magnetic minerals within this zone. 
3. Partially oxidized detrital magnetite (magheamite), biogenic magnetite and subordinate amounts of detrital hematite are present above the RMTZ. These magnetic minerals are sequentially dissolved in the RMTZ. Below the RMTZ, magnetite and hematite grains survive.

4. The mineral diagnostic parameter, $\mathrm{S}_{-0.3 \mathrm{~T}}$, mimics the decreasing patterns of the concentration-dependent parameters. Above the RMTZ, $\mathrm{S}_{-0.3 \mathrm{~T}}$ has a high value of 0.98 , which decreases to 0.93 at the bottom of the RMTZ. Only the magnetically soft component seems to undergo depletion in the RMTZ, while high-coercivity minerals survive. This implies that hematite is relatively resistant to diagenesis, whereas magnetite and maghemite are easily dissolved. This interpretation is also supported by the nearstable downcore HIRM patterns.

5. The granulometric parameters $\left(\chi_{\mathrm{ARM}} / \chi\right)$ also show large decreases within the RMTZ. This may imply a coarsening of the dominant magnetite in this zone. Below the RMTZ, $\chi_{\text {ARM }} / \chi$ starts to increase. This may suggest a further reduction in the grain size of the surviving magnetic minerals down to the bottom of the cores.

6. The depth of RMTZ is different among the cores. A relatively higher supply of organic carbon at the near-shore sites may result in anoxic environments and the shallower depth of the lower boundary of the RMTZ.

Acknowledgments. We are grateful to Prof. M. Fukuhara (Okayama University of Science), Dr. N. Ishikawa (Kyoto University) and Dr. T. Kanamatsu (Japan Agency for Marine-Earth Science and Technology) for the use of their facilities, and Dr. R. Egli for the use of the software for the IRM decomposition analysis. We sincerely thank Dr. M. Ikehara (Kochi University) and Dr. J. S. Stoner (Oregon State University) for providing us with their unpublished data and valuable discussions. Critical comments from Prof. H. Tanaka, Dr. C.-S. Horng and an anonymous reviewer have also been invaluable. This work was supported by the SASAGAWA Research Grant no. 15-352 M to N. K.

\section{References}

Berner, R. A., Early Diagenesis: A Theoretical approach, 241 pp., Princeton University Press, Princeton, 1980.

Bloemendal, J. J., J. W. King, A. Hunt, P. B. DeMenocal, and A. Hayashida, Origin if the sedimentary magnetic record at Ocean Drilling Program sites on the Owen Ridge, western Arabian Sea, J. Geophys. Res., 98, 4199-4219, 1993.

Bloemendal., J., J. W. King, F. R. Hall, and S.-J. Doh, Rock magnetism of late Neogene and Pleistocene deep-sea sediments: relationship to sediment source, diagenetic processes, and sediment lithology, J. Geophys. Res., 97, 4361-4375, 1992.

Canfield, D. E. and R. A. Berner, Dissolution and pyritization of magnetite in anoxic marine sediments, Geochim. Cosmochim. Acta, 51, 645-659, 1987.

Egli, R., Analysis of the field dependence of remanent magnetization curves, J. Geophys. Res., 108, 10.1029/2002JB002023, 2003.

Egli, R., Characterization of individual rock magnetic components by analysis of remanence curves: 3 Bacterial magnetite and natural processes in lakes, Phys. Chem. Earth, 29, 869-884, 2004.

Evans, M. E. and F. Heller, Environmental Magnetism: Principles and applications of enviromagnetics, 299 pp., Elsevier Science Press, USA, 2003.

Gorbarenko, S. A., T. A. Khusid, I. A. Basov, T. Oba, J. R. Southon, and I. Koizumi, Glacial Holocene environment of the southeastern Okhotsk Sea: evidence from geochemical and paleontological data, Palaeogeogr. Palaeoclimatol. Paleonencol., 177, 237-263, 2002.

Heslop, D., G. McIntosh, and M. J. Dekkers, Using time- and temperaturedependent Preisach models to investigate the limitations of modeling isothermal remanent magnetization acquisition curves with cumulative $\log$ Gaussian functions, Geophys. J. Int., 157, 55-63, 2004.
Hilgenfeldt, K., Diagenetic dissolution of biogenic magnetite in surface sediments of the Bengula upwelling system, Int. J. Earth Sci., 88, 630$640,2000$.

Horiuchi, N. and K. Fukushima, The characteristics of organic component in the surface sediments off Shiretoko peninsula in the Okhotsk Sea, in Preliminary reports on Researches in the 2001 fiscal year: "Marine Geological and Geophysical Study on the Collision zone of Kurile and Northeast Japan Arcs in the area of Okhotsk Sea", GSJ Interim Report no.25, pp.199-208, Geological Survey of Japan, 2002 (in Japanese).

Hunt, C. P., B. M. Moskowitz, and S. K. Bannerjee, Magnetic properties of rocks and minerals, in Rock Physics and Phase Relations: a handbook of physical contents, pp. 189-204, edited by T. J. Ahrenns., AGU, USA, 1995.

Ikehara, K., A. Noda, H. Katayama, and T. Maekawa, The distribution of seafloor surface sediment from Soya strait to Kitamiyamat bank area, in Preliminary reports on Researches in the 2000 fiscal year: "Marine Geological and Geophysical Study on the Collision zone of Kurile and Northeast Japan Arcs", and "Study on evaluation of marine active faults, in the areas of Okhotsk Sea and off Tokai". GSJ Interim Report no. MG/01/1, pp. 78-90, 2001 (in Japanese).

Ikehara, K., J. Komori, C. Shimada, H. Katayama, and A. Noda, Late Holocene marine environmental changes and its relation to climatic changes in the southwestern Okhotsk Sea, Proceedings of 17th International Symposium on Okhotsk Sea and Sea Ice: Okhotsk Sea \& Cold Ocean Research Association, 98-103, 2002.

Itaki, T. and K. Ikehara, Middle to late Holocene changes of the Okhotsk Sea Intermediate Water and their relation to atmospheric circulation, Geophys. Res. Lett., 31, 10.1029/2004GL021384, 2004.

Kao, S.-J., C.-H. Horng, A. P. Roberts, and K.-K. Liu., Carbon-sulfur-iron relationships in sedimentary rocks from southwestern Taiwan: influence of geochemical environment on greigite and pyrrhotite formation, Chem. Geol., 203, 153-168, 2003.

Katayama, H., A. Noda, and K. Ikehara, The environment of Okhotsk Sea, off Monbetsu, in Preliminary reports on Researches in the 2001 fiscal year: "Marine Geological and Geophysical Study on the Collision zone of Kurile and Northeast Japan Arcs, in the area of Okhotsk Sea", GSJ Interim Report no. 25, pp. 46-57, Geological Survey of Japan, 2002 (in Japanese).

Kawahata, H., H. Ohshima, C. Shimada, and T. Oba, Terrestrialoceanic environmental changes in the southern Okhotsk sea during the Holocene, Quat. Int., 108, 2, 67-76, 2003.

Kawamura, N., K. Ikehara, H. Oda, and M. Torii, Rock magnetic study of Holocene marine sediments recovered from the Okhotsk Sea: study of two core sediments near Kitamiyamato Bank off Abashiri, Hokkaido, Quaternary Res., 42, 83-97, 2003 (in Japanese with English abstract).

Kimura, N. and M. Wakatsuchi, Process controlling the advance and retreat of sea ice in the Sea of Okhotsk, J. Geophys. Res., 104, 11137-11150, 1999.

King, J. W., S. K. Banerjee, J. Marvin, and O. Ozdermir, A comparison of different magnetic methods for determining the relative grain size of magnetite in natural material: some results from lake sediments, Earth Planet. Sci. Lett., 59, 404-419, 1982.

Komori, J., H. Fukusawa, K. Ikehara, H. Katayama, and A. Noda, The variations of organic carbon and elements constitution in the sediments from the Okhotsk Sea, eastern Kitamiyamato Bank, in Preliminary reports on researches in the 2000 fiscal year: "Marine geological and geophysical study on the collision zone of Kurile and northeast Japan Arcs" and "Study on evaluation of marine active faults in the Areas of Okhotsk Sea and Off-Tokachi ", GSJ Interim Report no. MG/01/1, pp.197-205, Geological Survey of Japan, 2001 (in Japanese).

Komori, J., M. Utuki, H. Fukusawa, K. Ikehara, H. Katayama, and A. Noda, The variation of organic carbon in the sediments from the Okhotsk Sea off northwestern Shiretoko peninsula, in Preliminary reports on Researches in the 2001 fiscal year: "Marine Geological and Geophysical Study on the Collision zone of Kurile and Northeast Japan Arcs, in the area of Okhotsk Sea", GSJ Interim Report no. 25, pp. 199208, Geological Survey of Japan, 2002 (in Japanese).

Komori, J., H. Fukusawa, and K. Ikehara, Paleoceanograhic change in the southwestern Okhotsk Sea since the Last Glacial Maximum. 111th Conference Abstract of Geol. Soc. Japan, pp. 299, 2004 (in Japanese).

Kruiver, P. P. and H. F. Passier, Coercivity analysis of magnetic phases in sapropel S1 related to variations in redox conditions, including an investigation of the S-ratio, Geochem. Geophys. Geosyst., 14, 2001GC000181, 2001.

Leslie, B. W., D. E. Hammond, W. M. Berelson, and S. P. Lund, Diagenesis in anoxic sediments from the California continental borderland and its 
influence on iron, sulfur, and magnetite behavior, J. Geophys. Res., 95, 4453-4470, 1990a.

Leslie, B. W., S. P. Lund, and D. E. Hammond, Rock magnetic evidence for the dissolution and authigenic growth of magnetic minerals within anoxic marine sediments of the California continental borderland, $J$. Geophys. Res, 95, 4437-4452, 1990 b.

Liu, J., R. Zhu, A. P. Roberts, S. Li, and J.-H. Chang, High-resolution analysis of early diagenetic effects on magnetic minerals in post-middleHolocene continental sediments from the Korea Strait, J. Geophys. Res., 109, 10.1029JB002813, 2004.

Lowrie, W., Identification of ferromagnetic minerals in a rock by coercivity and unblocking temperature properties, Geophys. Res. Lett., 17, 159162, 1990.

Machida, H. and F. Arai, Atlas of Volcanic Ash, 276 pp., Tokyo University Press, Tokyo, Japan, 2003 (in Japanese).

Noda, A., H. Katayama, and K. Ikehara, The submarine sediments around Kitamiyamato Bank, off Monbetsu, in Preliminary reports on Researches in the 2001 fiscal year: "Marine Geological and Geophysical Study on the Collision zone of Kurile and Northeast Japan Arcs, in the area of Okhotsk Sea”, GSJ Interim Report no. 25, pp. 63-72, Geological Survey of Japan, 2002 (in Japanese).

Özdermir, Ö., D. J. Dunlop, and B. M. Moskowitz, The effect of oxidation on the Verwey transition in magnetite, Geophys. Res. Lett., 20, 16711674, 1993.

Passier, H. F. and M. J. Dekkers, Iron oxide formation in the active oxidation front above sapropel S1 in the eastern Mediterranean Sea as derived from low-temperature magnetism, Geophys. J. Int., 150, 230-240, 2002.

Roberts, A. P. and B. J. Pillans, Rock magnetism of lower/middle Pleistocene marine sediments, Wanganui Basin, New Zealand, Geophys. Res. Lett., 20, 839-842, 1993.

Robinson, S. G., J. T. Sahota, and S. Oldfield, Early diagenesis in North Atlantic abyssal plain sediments characterized by rock-magnetic and geochemical indices, Mar. Geol., 163, 77-107, 2000.

Rey, D., K. J. Mohamed, A. Bernabeu, B. Rubio, and F. Vilas, Early diagenesis of magnetic minerals in marine transitional environments: geochemical signatures of hydrodynamic forcing, Mar. Geol., 215, 215236, 2005.

Shimada, C., M. Murayama, K. Aoki, T. Nakamura, S. Hasegawa, and T. Oba, Holocene Paleoceanography in the SW part of the Sea of Okhotsk: diatom record, Quaternary Res., 39, 39-449, 2000 (in Japanese with
English abstract).

Shimada, C., K. Ikehara, Y. Tanimura, and S. Hasegawa, Millennial-scale variability of Holocene hydrography in the southwestern Okhotsk Sea: diatom evidence, Holocene, 14, 641-650, 2004.

Tanabe, T. and T. Sakamoto, The grain distribution and the mineral composition of the marine sediments and its origin in the southwestern Okhotsk Sea collected by the GH00 and GH01 cruises. in Preliminary reports on Researches in the 2001 fiscal year: "Marine Geological and Geophysical Study on the Collision zone of Kurile and Northeast Japan Arcs, in the area of Okhotsk Sea", GSJ Interim Report no. 25, pp. 199208, Geological Survey of Japan, 2002 (in Japanese).

Takahashi, K., The Bering and Okhotsk Seas: modern and past paleoceanographic changes and gateway impact, J. Asian Earth Sci., 16, 49-58, 1998.

Takizawa, T., Characteristics of the Soya Warm Current in the Okhotsk Sea, J. Oceanogr., 38, 281-292, 1982.

Torii, M., Low-temperature oxidation and subsequent downcore dissolution of magnetite in deep-sea sediments, ODP Leg 161 (Western Mediterranean), J. Geomag. Geoelecter., 49, 1223-1245, 1997.

Walden, J., F. Oldfield, and J. Smith, Environmental Magnetic a Practical Guide, Quaternary Research Association, 243 pp, Quaternary Research Association, London, 1999.

Watanabe, T. and M. Wakatsuchi, Formation of $26.8-26.9 \delta \theta$ water in the Kurile basin of the sea of Okhotsk as a possible origin of North Pacific Intermediate Water, J. Geophys. Res., 103, 2849-2865, 1998.

Yamazaki, T., A. L. Abdelaziz, and K. Ikehara, Rock-magnetic changes with reduction diagenesis in Japan Sea surface sediments and preservation of geomagnetic secular variation in inclination during the last 30,000 years, Earth Planets Space, 55, 327-340, 2003.

Yamazaki, T. and H. Oda, The result of anisotropy of magnetic susceptibility and natural remanent magnetization of the submarine sediment around Kitamiyamato Bank. in Preliminary reports on Researches in the 2001 fiscal year: "Marine Geological and Geophysical Study on the Collision zone of Kurile and Northeast Japan Arcs, in the area of Okhotsk Sea”, GSJ Interim Report no. 25, pp. 199-208, Geological Survey of Japan, 2002 (in Japanese).

N. Kawamura (e-mail: kwmr@gaia.h.kyoto-u.ac.jp), H. Oda, K. Ikehara, T. Yamazaki, K. Shioi, S. Taga, S. Hatakeyama, and M. Torii 